\title{
SYNTHESIS OF RANDOM COPOLYMERS OF 2,6-DI(THIOPHEN-2-YL)ANILINE AND 2,2'-(THIOPHEN-2,5- DIYL)DIANILINE WITH ANILINE AND ITS EVALUATION IN ORGANIC SOLAR CELLS
}

\author{
I.A. JESSOP' ${ }^{1}$ P.P. ZAMORA', F.R. DÍAZ2*, M.A. DEL VALLE', J.C. BERNEDE ${ }^{4}$ \\ ${ }^{1}$ Universidad de Tarapacá, Facultad de Ciencias, Departamento de Química, Av. General Velásquez 1775, Arica, Chile. \\ ${ }^{2}$ Pontificia Universidad Católica de Chile, Facultad de Química, Departamento de Química Orgánica, Laboratorio de Polímeros, \\ Av. Vicuña Mackenna 4860, Santiago de Chile \\ ${ }^{3}$ Pontificia Universidad Católica de Chile, Facultad de Química, Departamento de Química Inorgánica, Laboratorio de Electroquímica de Polímeros, \\ Av. Vicuña Mackenna 4860, Santiago de Chile \\ ${ }^{4}$ Université de Nantes, MOLTECH-Anjou,CNRS, UMR 6200, 2 rue de la Houssinière, BP 92208, Nantes, F-44000 France
}

(Received: December 18, 2013 - Accepted: January 30, 2014)

\begin{abstract}
The present work deals with copolymers synthesized by reacting aniline units or blocks with 2,6-di(thiophen-2-yl)aniline and 2,2'-(thiophen-2,5-diyl)dianiline monomers. Characterization by spectroscopic techniques such as FT-IR, UV-vis, 1H-NMR corroborated the formation of true copolymers. Synthesized products showed improved solubility and better photovoltaic efficiency than the respective homopolymers. The latter is due to the presence of a greater number of quinoid units, capable of promoting charge carriers generation. However, the low mobility of the charge carriers, that increases copolymers resistivity, would be responsible for an efficiency improvement of just one order of magnitude with respect to the homopolymers.
\end{abstract}

Keywords: Aniline derivative copolymers, optical and thermal studies, bandgap, photovoltaic efficiency.

\section{INTRODUCTION}

In recent decades intrinsically conductive polymers have attracted considerable attention, giving rise to the developed of a variety of technological applications, e.g. light emitting diodes (LEDs) [1], anti-corrosion coatings [2], integrated circuits and transistors [3], rechargeable batteries [4] and photovoltaic devices [5], among others. The wide versatility of these compounds stems mainly from their electronic and optical properties, high thermal and environmental stability and ease of preparation [6]. Polyaniline (PANI), polythiophene (PTH) and their corresponding derivatives occupy a privileged place within this family of materials and have been extensively studied [7-12]. In previous works the possibility of enhancing the properties of these polymers by designing monomers containing both aniline and thiophene units, i.e. hybrid precursors, was set forth. This fact was successfully corroborated in such investigations [13-14].

To complement the work, in the present study the polymerization of 2,6-di(thiophen-2-yl)aniline and 2,2'-(thiophen-2,5-diyl)dianiline monomers has been carried out by adding aniline units during the course of the reaction. It was demonstrated [13] that monomers growth occurs only through aniline or anilines unit(s), whereby the incorporated aniline units would increase the PANI-like character of the macromolecules and the spacing between monomers, which would provide greater flexibility to the polymer chains, favoring its processability in solution, and would modify its optical and electronic properties and thermal stability. The novel obtained products were characterized spectroscopic, thermal and electrochemically and evaluated as the active layer in organic solar cells.

\section{EXPERIMENTAL}

Chemicals used in this research were purchased from Sigma-Aldrich while solvents were Merck and used as received, except aniline that was bi-distilled at reduced pressure.

Instrumentation

${ }^{1} \mathrm{H}$ NMR spectra were recorded on a $400 \mathrm{MHz}$ Bruker spectrometer. FTIR spectra of the polymers dispersed in $\mathrm{KBr}$ pellets were recorded on a Bruker Vector 22 spectrometer. UV-Vis spectra were obtained on a SPECORD 40 Analitik Jena spectrophotometer using $1 \mathrm{~cm}$ optical path quartz cells. The solubility was determined in various commonly used organic solvents, e.g. DMSO, NMP, THF, $\mathrm{CHCl}_{3}$, etc. at $25^{\circ} \mathrm{C}$. Thermogravimetric analysis (TGA) was performed on a Mettler TA-3000 Thermal Analysis System equipped with a TC-10A processor and a TG-50 thermo-balance with a Mettler MT5 microbalance, heating the samples from 25 to $900{ }^{\circ} \mathrm{C}$ at a rate $10{ }^{\circ} \mathrm{C}$ min ${ }^{1}$ under nitrogen. Glass transition temperature $(\mathrm{Tg})$ was measured using differential scanning calorimetry (DSC) technique on a Mettler-Toledo DSC 821 calorimeter. The first step was to remove sample adsorbed moisture by heating from -100 to $110^{\circ} \mathrm{C}$, and then from 25 to $300^{\circ} \mathrm{C}$ during the subsequent cycles. All measurements were accomplished under nitrogen at $20{ }^{\circ} \mathrm{C} \mathrm{min}^{-1}$ heating rate. Photovoltaic devices were assembled according to the following structure: indium tin oxide (ITO) anode/anode buffer layer $\left(\mathrm{MoO}_{3}, \mathrm{CuI}\right.$ or $\mathrm{CuI} /$ $\mathrm{MoO}_{3}$ )/undoped electron donor polymer (coPANIA or coPANIB)/fullerene $\left(\mathrm{C}_{60}\right)$ /exciton blocking layer (BCP)/Al cathode. The device was prepared by sublimation at $1 \times 10^{-7} \mathrm{~atm}$. The thin film deposition rate and thickness were estimated in situ using a quartz monitor. The deposition rate of the organic layers was $0.05 \mathrm{~nm} \mathrm{~s}^{-1}$. The film thickness was $8-20 \mathrm{~nm}, 40 \mathrm{~nm}$ and $9 \mathrm{~nm}$ for the electron donor polymer, $\mathrm{C}_{60}$ and $\mathrm{BCP}$ respectively. The ITO and Al films were $100 \mathrm{~nm}$ thick. The effective area of each cell was $0.25 \mathrm{~cm}^{2}$. Electrical characterization was conducted on an automated I-V tester, in the dark and under global AM 1.5G simulated solar illumination. Photovoltaic cell efficiency was measured using a calibrated solar simulator (Oriel 300W) at 100 $\mathrm{mW} \mathrm{cm}{ }^{-2}$ light intensity.

Mononers and polymers synthesis

The monomeric units showed in Fig. 1 were previously prepared [13] using the Suzuki-Miyaura cross-coupling reaction [15] between 2,6-dibromoaniline and 2-thienylboronic acid for 2,6-di(thiophen-2-yl)aniline (MonA) and between 2,5-dibromothiophene and 2-(4,4,5,5-tetramethyl-1,3,2-dioxaborolan2-yl)aniline for 2,2'-(thiophen-2,5-diyl)dianiline (MonB), in the presence of $\mathrm{Pd}\left[\left(\mathrm{PPh}_{3}\right)_{4}\right]_{2} \mathrm{Cl}_{2}$ as catalyst and $\mathrm{K}_{2} \mathrm{CO}_{3}$ as base in 1,4-dioxane. The compounds were purified by column chromatography to afford a $95 \%$ yield.

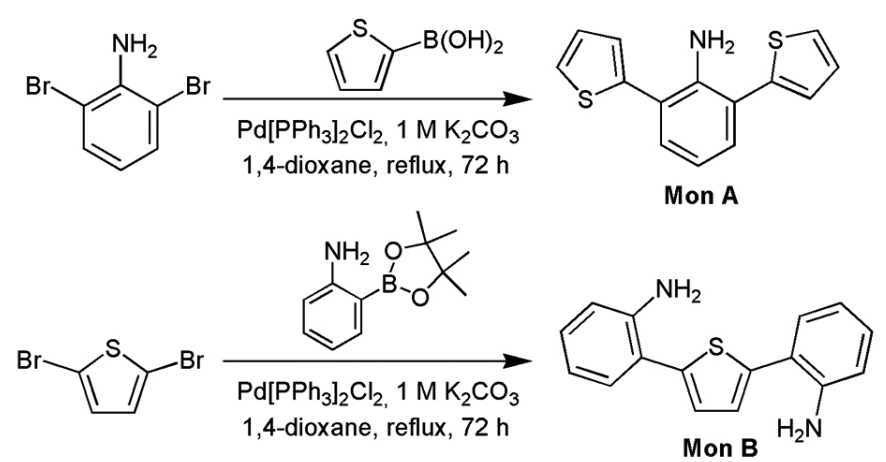

Figure 1. Synthesis of MonA and MonB monomer units.

Chemical polymerization was performed using Chan et al. method [16]. $1 \mathrm{mmol}$ of MonA or MonB and $4 \mathrm{mmol}$ of anhydrous $\mathrm{FeCl}_{3}$ was dissolved in $\mathrm{CHCl}_{3}$ in the dark at $0-5{ }^{\circ} \mathrm{C}$ and the mixture was stirred for $1 \mathrm{~h} .1 \mathrm{mmol}$ of aniline in $10 \mathrm{~mL} \mathrm{CHCl}_{3}$ was then slowly added and the mixture was stirred for $24 \mathrm{~h}$ at room temperature. The obtained polymers, coPANIA and coPANIB, 
were washed with a methanol/water mixture for $24 \mathrm{~h}$, dedoped by stirring with $50 \%$ aqueous hydrazine for $24 \mathrm{~h}$, washed with $\mathrm{CHCl}_{3}$ using a Soxhlet apparaus and vacuum dried for $24 \mathrm{~h}$. The copolymers yield was $55 \%$ of a black solid (Fig. 2).
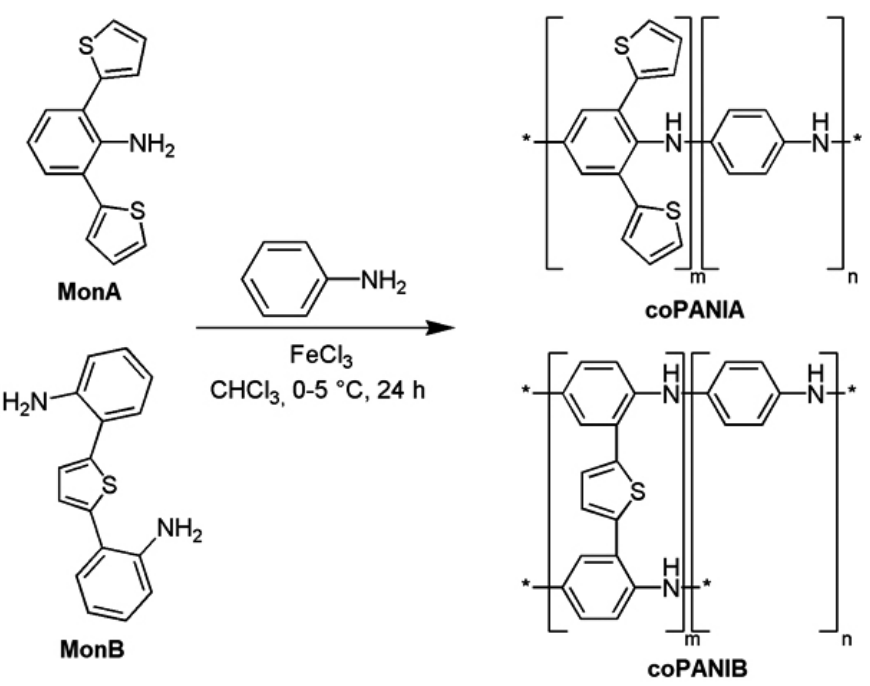

Figure 2 Synthesis of coPANIA and coPANIB random copolymers.

\section{RESULTS AND DISCUSSION}

\section{FT-IR and NMR spectroscopy}

Figure 3 shows FT-IR spectra of both coPANIA and coPANIB random copolymers. At about $3450-3350 \mathrm{~cm}^{-1}$ a strong absorption band is observed corresponding to $\mathrm{N}-\mathrm{H}$ stretching of aniline units. $\mathrm{C}-\mathrm{H}$ stretching vibrations of aromatic rings were observed between $3100-3000 \mathrm{~cm}^{-1}$. Two absorption peaks characteristic of PANI and its derivatives appeared close to 1600 and $1450 \mathrm{~cm}^{-1}$. These signals correspond to quinone and benzene ring-stretching deformation, respectively. The amount of oxidizing agent used was optimized in such a way that the ratio of the relative intensities of the two signals is close to unity, as long as the copolymers are obtained as emeraldine, their most conductive state [17]. As for thiophene unit or units, a highly intensive absorption band at 698 $\mathrm{cm}^{-1}$ for coPANIA and $750 \mathrm{~cm}^{-1}$ for coPANIB was obtained. As previously described [18], these signals are generated by $\mathrm{C}-\mathrm{H}$ out of plane (oop) bending from 2-substituted and 2,5-disubstituted thiophene units, respectively.

In contrast to infrared spectra of the corresponding PolyA and PolyB [13] homopolymers, some differences were found. A new signal was exhibited at $1510 \mathrm{~cm}^{-1}$ for coPANIA and $1570 \mathrm{~cm}^{-1}$ for coPANIB, that would reveal the presence of aniline units or blocks inserted during the polymerization. This would arise from C-N stretching or C-C stretching vibrations and from C-Nsec deformation, respectively [17]. On the other hand, the absorption bands assigned to the out of plane vibration of aniline ring or rings, 802 and $813 \mathrm{~cm}^{-1}$ for MonA and MonB homopolymers [13], respectively, appeared shifted to 793 and $824 \mathrm{~cm}^{-1}$. This would reflect the addition of aniline units would occur via such rings, conferring greater substituted polyaniline-like character to the synthesized polymers.

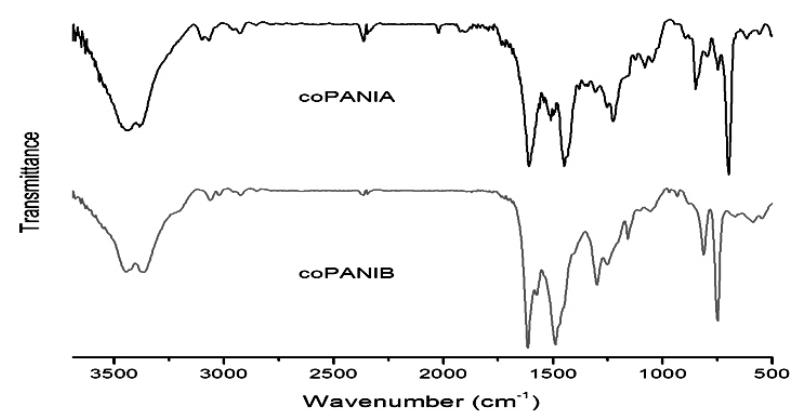

Figure 3. FT-IR spectra of coPANIA and coPANIB in undoped state.
coPANIA and coPANIB ${ }^{1} \mathrm{H}$ NMR spectra were run in DMSO-d solvent in which they are partially soluble. Because very broad bands were observed that precluded their correct interpretation, oligomers, obtained two hours after the polymerization onset, were prepared.

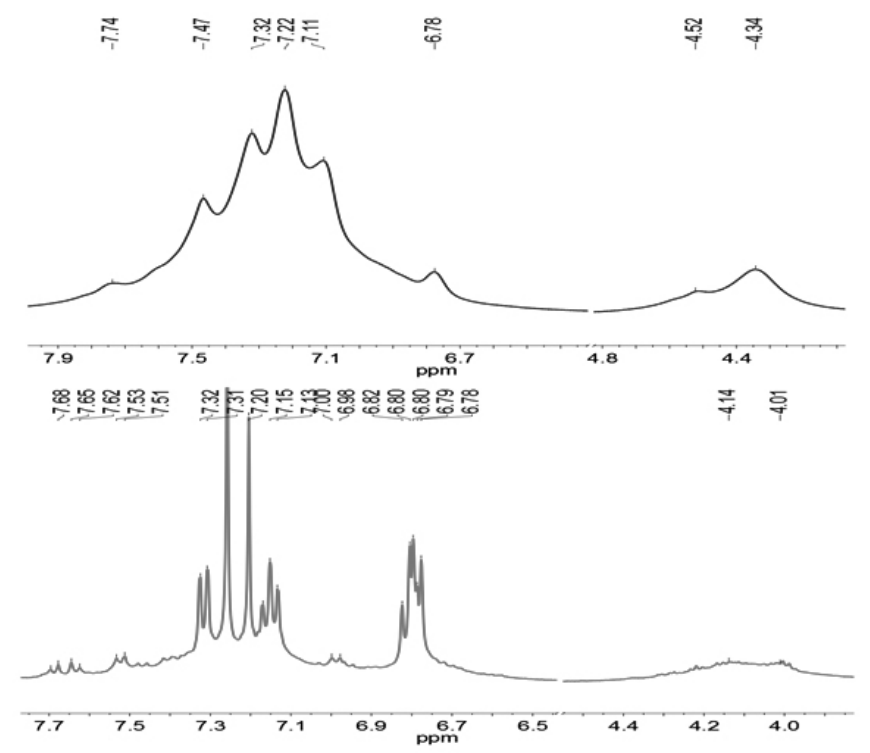

Figure 4. coPANIA (up) and coPANIB (down) ${ }^{1} \mathrm{H}$ NMR oligomers spectra in DMSO-d6.

Despite the short time for the reaction to proced, it is possible to distinguish two relevant changes as compared to the spectra of the monomeric units. For coPANIA, the band at $6.78 \mathrm{ppm}$, assigned to the para proton of the aniline central unit, decreases its intensity relative to the rest of the aromatic signals; for coPANIB, one of the signals between 6.85 and $6.75 \mathrm{ppm}$, ascribed to ortho and para protons of aniline side units, changes its resonance pattern. As for the signals associated to thiophene units, they exhibited no modifications.. This means the polymer growth occurs just through aniline unit(s) of the monomers, corroborating thus the results of a previous work [13]. On the other hand, in both cases the appearance of weak signals at about $7.50 \mathrm{ppm}$, ascribed to PANI chain benzenoid and quinoid aromatic protons, were observed [14, 1920]. At $4.00 \mathrm{ppm}$, where the signal associated to amino groups shows up, a second band, downfield shifted, starts emerging. This would account for the formation of C-NH-C bonding and, hence, for the conjugation extent of the polymer chains. These results are consistent with those found in the FT-IR studies that would indicate the random incorporation of aniline units to the monomers through their aniline moieties, obtaining real copolymers displaying substituted PANI-like character.

Solubility

Table 1 summarizes solubility results for copolymers derived from MonA and MonB. These assays were conducted at $25^{\circ} \mathrm{C}$ and a concentration of $1 \mathrm{mg}$ of polymer $/ 1 \mathrm{~mL}$ of solvent.

Table 1. Solubility of the studied polymers in commonly used organic solvents. aSlightly soluble. ${ }^{\mathrm{b} I n s o l u b l e .}$

\begin{tabular}{|c|c|c|c|c|c|c|c|}
\hline \multirow{2}{*}{ Polymer } & \multicolumn{7}{|c|}{ Solvent } \\
\cline { 2 - 8 } & $\mathrm{CH}_{3} \mathrm{CN}$ & $\mathrm{CH}_{3} \mathrm{Cl}$ & DMSO & NMP & DMF & THF & Tol. \\
\hline coPANIA & $\pm{ }^{\mathrm{a}}$ & \pm & \pm & \pm & \pm & ${ }^{\mathrm{b}}-$ & - \\
\hline coPANIB & \pm & \pm & \pm & \pm & \pm & - & - \\
\hline
\end{tabular}

Because of the low solubility of the products, it was not possible to carry out GPC studies nor viscosimetric measurements. Compared to the corresponding homopolymers [13], a slight improvement in the solubility of the products was observed. The random incorporation of aniline units or blocks would promote the formation of less regular polymers, which affects the strength of intermolecular interactions and provides more flexibility to the chains. Notwithstanding the above, none of them was completely soluble in the used solvents.

Thermal Studies

Figure 5 shows the thermal degradation profiles and the respective 
differential curves for coPANIA and coPANIB copolymers, obtained by thermogravimetric analysis (TGA).

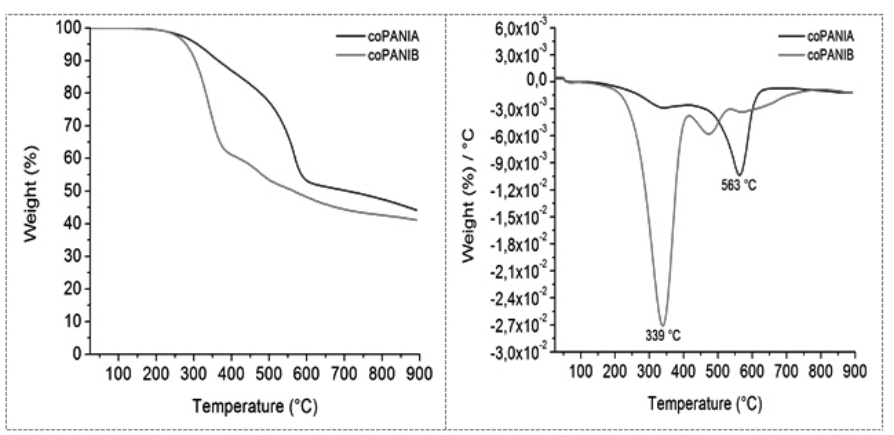

Figure 5. Thermogram (left) and differential thermogram (right) for coPANIA and coPANIB.

It is observed that coPANIA presents higher thermal stability than coPANIB. The $10 \%$ mass loss thermal decomposition temperature TDT ${ }_{10 \%}$ is $365^{\circ} \mathrm{C}$ and $304^{\circ} \mathrm{C}$, respectively. In addition, it was observed that above $250^{\circ} \mathrm{C}$ both compounds exhibited a significant mass loss that would be associated with polymer degradation. During this process crosslinking phenomenon already reported for PANI and its derivatives [21] would take place. The greater degradation rate for coPANIA and coPANIB occurs at $563{ }^{\circ} \mathrm{C}$ and $339{ }^{\circ} \mathrm{C}$, respectively.

Comparison of the thermal behavior of homo- [13] and copolymers, demonstrated the following:

- MonA derived polymers are more thermally stable than those derived from MonB: as MonA shows a single growing point (aniline central unit), the formed linear polymers would present more symmetry than those branched polymers derived from MonB (side aniline units), whereupon ordering and packing between chains would be facilitated.

coPANIA is less thermally stable than PolyA, despite its mass loss maximum rate takes place at similar temperatures. It was assumed that the introduction of aniline units between MonA promotes a loss of polymer symmetry, thereby decreasing the magnitude of the intermolecular forces between the chains.

coPANIB is thermally more stable than PolyB: due to the insertion of aniline units or blocks between MonB, the probability that the copolymer crosslinks through the ortho positions of benzenamines would be enhanced.

As for the results obtained from the study of differential scanning calorimetry (DSC), in both cases it can be seen an endothermic process above $200{ }^{\circ} \mathrm{C}$, which would be related to morphological changes of the PANIderived polymers [22-23]. A unique and distinct glass transition temperature for coPANIB and coPANIA was detected at 136 and $189^{\circ} \mathrm{C}$, respectively, corroborating thus the formation of true copolymers. In comparison with homopolymers [9], coPANIA and coPANIB $\mathrm{T}_{\mathrm{g}}$ is higher in both cases. The conjugation increase of the central chain provokes a shift of this property towards higher temperatures [24].

Table 2 summarizes the results obtained from thermal studies of MonA and MonB homo- and copolymers.

Table 2. Thermal properties of MonA and MonB homo- and copolymers derivatives.

\begin{tabular}{|c|c|c|}
\hline Polymer & $\mathrm{TDT} 10 \%\left({ }^{\circ} \mathrm{C}\right)$ & $\operatorname{Tg}\left({ }^{\circ} \mathrm{C}\right)$ \\
\hline PolyA & 512 & 133 \\
\hline coPANIA & 365 & 136 \\
\hline PolyB & 222 & 117 \\
\hline coPANIB & 304 & 189 \\
\hline
\end{tabular}

\section{Optical properties}

Figure 6 depicts UV-vis spectroscopy studies for coPANIA and coPANIB. To this purpose, $10 \mathrm{mg}$ of the sample was suspended in $2 \mathrm{~mL}$ of DMSO and stirred overnight. The sample was then filtered and the recovered extract was employed to perform the measurements.
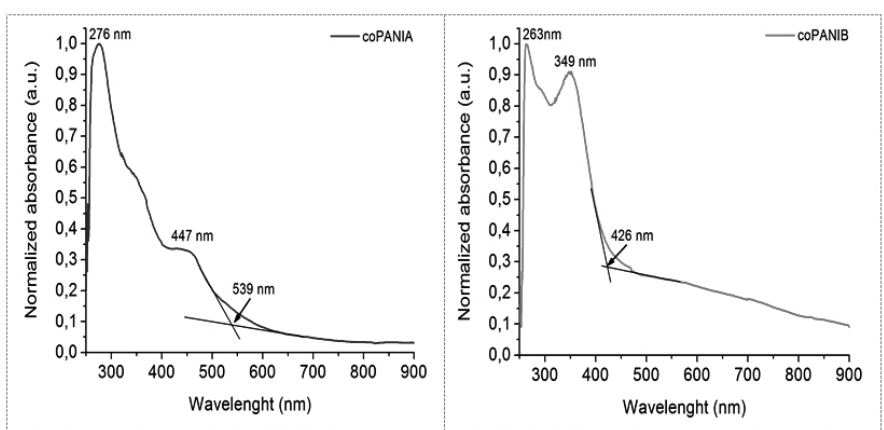

Figure 6. coPANIA (left line) and coPANIB (right line) UV-vis spectra

Soluble fraction absorption bands were almost the same as those found for the homopolymers, hence their assignments can be found in the corresponding work [13]. However, in the case coPANIA the signal appearing near 450 $\mathrm{nm}$, which could be related to polaron formation [25-27], is much more defined. This finding was ascribed to an easier oxidation of the aniline units that are incorporated into the polymer. This signal is also observed in the coPANIB spectrum, but now appears superimposed with the signal assigned to $\pi-\pi^{*}$ transitions of the thiophene ring. coPANIB also displayed a broad band reaching over the $800 \mathrm{~nm}$, that would reflect the electronic population associated to quinoid structures [14].

The optical bandgap, the energy barrier between HOMO and LUMO molecular orbitals, of each copolymer was determined from the intersection of the tangent line passing through the less energetic absorption band and the baseline. The obtained wavelength divides the constant $1242(\mathrm{Eg}=\mathrm{hc} / \mathrm{l})$, giving an estimate bandgap value in $\mathrm{eV}[13-14,28]$. According to the data shown in Fig. 6, the magnitude of this quantity is 2.30 and $2.92 \mathrm{eV}$ for coPANIA and coPANIB, respectively. These values are slightly higher than those determined for PolyA and PolyB [13], which would reflect a lower capacity to capture solar photons and hence lower efficiency of photovoltaic devices fabricated from them. Consequently, the addition of aniline units has generated an impairment in the optical properties of the copolymers.

\section{Photovoltaic devices}

In order to obtain reproducible and comparable results to those reported for the homopolymers [13], bilayered solar cells prototypes were fabricated. Due to coPANIA and coPANIB low solubility they were deposited on the anode (FTO) using high-vacuum sublimation. Different buffer layers were tested being a double-layered made of $\mathrm{MoO}_{3} / \mathrm{CuI}$ the one that provided the best efficiency [29]. Active layers (synthesized copolymers) of various thicknesses were tried. All of them exhibited high series resistance. Figure 7 and Table 3 show the electrical features of the prototypes.

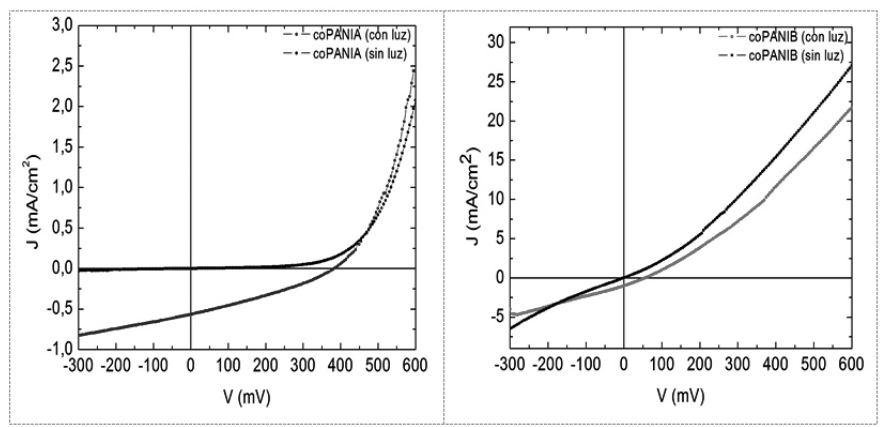

Figure 7. J-V characteristics of photocells fabricated from MonA and MonB copolymers with aniline. Assembly: ITO $(100 \mathrm{~nm}) / \mathrm{MoO}_{3}(3 \mathrm{~nm}) / \mathrm{CuI}$ $(2.5 \mathrm{~nm}) /$ coPANIA $(10 \mathrm{~nm})$ or coPANIB $(15 \mathrm{~nm}) / \mathrm{C} 60(40 \mathrm{~nm}) / \mathrm{BCP}(8 \mathrm{~nm}) /$ $\mathrm{Al}(100 \mathrm{~nm}) / \mathrm{Se}(20 \mathrm{~nm})$.

Table 3. Photocells electrical parameters

\begin{tabular}{|c|c|c|c|c|}
\hline Polymer & $\mathrm{V}_{\mathrm{oc}}(\mathrm{V})$ & $\begin{array}{c}\mathrm{J}_{\mathrm{sc}}(\mathrm{mA} \\
\left.\mathrm{cm}^{-2}\right)\end{array}$ & $\mathrm{FF}(\%)$ & $\eta(\%)$ \\
\hline coPANIA & 0.38 & 0.57 & 31.54 & $6.80 \cdot 10^{-2}$ \\
\hline coPANIB & 0.06 & 1.02 & 26.84 & $1.51 \cdot 10^{-2}$ \\
\hline
\end{tabular}


Comparison with the data presented in a previous work demonstrated that the prototypes made from MonB derivatives exhibited higher current density, therefore it might be said that they are more conductive. However, analysis of the short circuit current $\mathrm{J}_{\mathrm{sc}}$ of all photocells (including MonA products), revealed it was very low. This can be ascribed to the high resistivity of the polymers, as a result of branching in their structures (polyB and coPANIB) or main chain torsion (PolyA and coPANIA), which would hinder the charge carrier mobility in the polymeric chains [13] and would account for the high value of their bandgaps. These hypotheses will be assessed through the respective study of hole-mobility.

Contrary to what it was assumed, prototypes prepared with coPANIA and coPANIB exhibited better efficiency than the respective homopolymers (one order of magnitude higher). It was assumed that this difference was due to a greater amount of photo-generated charge carriers from quinoid units that provoked a current density increase with respect to the monomers, or a greater difference between the copolymer LUMOs with $\mathrm{C}_{60}$, that would explain a better excitons separation. The presence of quinoid units is consistent with FT-IR, $\mathrm{UV}$-vis and ${ }^{1} \mathrm{H}-\mathrm{NMR}$ spectroscopic results. However, these results are still low. Consequently, this series of homo- and copolymers proved to be unsuitable for the proposed application. Nevertheless, further work with these products in other technological applications has not been ruled out.

\section{CONCLUSIONS}

The controlled introduction of aniline units during MonA and MonB chemical polymerization allows true copolymers to be obtained. These products exhibit, thanks to overlapping increase of their molecular orbitals, improved solubility and higher glass transition temperature with respect to those of the corresponding homopolymer.

Photovoltaic modules assembled from coPANIA and coPANIB displayed better efficiency compared to PolyB and PolyA [13]. However, the high resistivity of their deposits and large bandgap were responsible for the efficiency to increase by just one order of magnitude.

\section{ACKNOWLEDGEMENTS}

Financial support through project FONDECYT 1095165 is kindly acknowledged. IAJ and PPZ thank CONICYT for a Doctoral Scholarship and Project ECOS/CONICYT C09E02.

\section{REFERENCES}

1. H. Sasabe, J. Kido, J. Mater. Chem. C 123, 1699, (2013).

2. T. Ohtsuka, Int. J. Corros. 2012, 915090, (2012).
3. J. D. Yuen, F. Wudl, Energy Environ. Sci. 6, 392, (2013).

4. L. Nyholm, G. Nyström, A. Mihranyan, M. Strømme, Adv. Mater. 23, 3751, (2011).

5. D. Gendron, M. Leclerc, Energy Environ. Sci. 4, 1225, (2011).

6. M.S. AlSalhi, J. Alam, L.A. Dass, M. Raja, Int. J. Mol. Sci. 12, 2036, (2011).

7. D. Li, J. Huang, R.B. Kaner, Acc. Chem. Res. 42, 135, (2009).

8. M.R.A. Alves, H.D.R. Calado, T. Matencio, C.L. Donnici, Quim. Nov. 33 2165, (2010).

9. E. Ortega, F. Armijo, I. Jessop, M.A. del Valle, F.R. Díaz, J. Chil. Chem. Soc. 58 (4), 1959 (2013).

10. C.O. Sánchez, A. Isla, C. Bustos, F. Díaz, N. Gatic, J. Chil. Chem. Soc 55 (2), 233 (2010).

11. M.A. del Valle, M.A. Gacitúa, L.I. Canales, F.R. Díaz, J. Chil. Chem. Soc. 54 (3), 260 (2009).

12. A.S. Ribeiro, W.A. Gazotti, V.C. Nogueiera, D.A. Machado, P.F. dos Santos Filho, M.A. De Paoli, J. Chil. Chem. Soc. 49 (3), 197 (2004).

13. I.A. Jessop, P.P. Zamora, F.R. Díaz, M.A. del Valle, A. Leiva, L. Cattin, M. Makha, J.C. Bernède, Int. J. Electrochem. Sci. 7, 9502, (2012).

14. P.P. Zamora, M.B. Camarada, I.A. Jessop, F.R. Díaz, M.A. del Valle, L. Cattin, G. Louarn, J.C. Bernède, Int. J. Electrochem. Sci. 7, 8276, (2012).

15. A.E. Thompson, G. Hughes, A.S. Batsanov, M.R. Bryce, P.R. Parry, B. Tarbit, J. Org. Chem. 70, 388, (2005).

16. S.C. Ng, L.G. Xu, H.S.O. Chan, J. Mat. Sci. Lett. 16, 1738, (1997).

17. N.V. Bhat, D.T. Seshadri, R.S. Phadke, Synth. Met. 130, 185, (2002).

18. D.A. Marani, A.A. Entezami, Iran. J. Pol. Sci. Tech. 3, 2, (1994).

19. X. Wang, T. Sun, C. Wang, C. Wang, W. Zhang, Y. Wei, Macromol. Chem. Phys. 211, 1814, (2010).

20. P. Anilkumar, M. Jayakannan, J. App. Pol. Sci. 114, 3531, (2009).

21. W.F. Alves, E.C. Venancio, F.L. Leite, D.H.F. Kanda, L.F. Malmonge, J.A. Malmonge, L.H.C. Mattoso, Thermochim. Acta 502, 43, (2010).

22. S. Wang, F. Wang, X. Ge, Synth. Met. 16, 99, (1986).

23. H.S.O. Chan, S.C. Ng, W.S. Sim, S.H. Seow, K.L. Tan, B.T.G. Tan, Macromolecules 26, 144, (1993).

24. J.C. Chen, K. Rajendran, S.W. Huang, H.W. Chang, J. Polym. Res., 18, 1693, (2011).

25. M. Wan, J. Yang, J. Appl. Polym. Sci. 55, 399, (1995).

26. S.A. Chen, L.C. Lin, Macromolecules 28, 1239, (1995).

27. P. Ghosh, S.K. Siddhanta, S.R. Haque, A. Chakrabarti, Synth. Met. 123 83, (2001).

28. D.A.M. Egbe, B. Cornelia, J. Nowotny, W. Günther, E. Klemm, Macromolecules 36, 5459, (2003).

29. J.C. Bernède, L. Cattin, M. Makha, V. Jeux, P. Leriche, J. Roncali, V. Froger, M. Morsli, M. Addou, Sol. Energ. Mat. Sol. Cells 110, 107, (2013). 